\title{
Development and usage of concept inventories in an optical engineering program
}

Charles Joenathan, Robert Bunch, Zoran Milanovic

Charles Joenathan, Robert M. Bunch, Zoran Milanovic, "Development and usage of concept inventories in an optical engineering program," Proc. SPIE 9664, Ninth International Topical Meeting on Education and Training in Optics and Photonics, 96640B (24 October 2005); doi: 10.1117/12.2207687

SPIE Event: Ninth International Topical Meeting on Education and Training in Optics and Photonics, 2005, Marseille, France 


\title{
Ref ETOP029
}

\section{Development and usage of concept inventories in an optical engineering program}

\author{
Charles Joenathan, Robert M. Bunch, and Zoran Milanovic
}

Department of Physics and Optical Engineering, Rose-Hulman Institute of Technology 5500 Wabash Avenue, Terre Haute, IN 47803, USA ( www.rose-hulman.edu)

\section{Abstract}

Education in optics has evolved in the last decade into an application and enabling technology field and it is emerging as an engineering field in the last couple of years. Therefore, as a newly evolving program, the emphasis is placed on the overall learning outcomes of the students. In that regard we have developed concept inventory questions in optical engineering to monitor and assess improvements in student learning. The concept inventory questions are given to students twice during a course, one at first day of class and the same questionnaire is given to them during the last day of class. The pre-class test is used to assess prior knowledge of the students and the second test is used to measure the learning experience of the students. The results of the test are used to monitor and improve overall education experience of the students.

\section{Introduction}

\section{Summary}

RHIT is an undergraduate science and engineering institution although we have an active master's level graduate program in many areas. The Department of Physics and Optical Engineering offers B. S. degrees in Optical Engineering, B. S. degree in Engineering Physics, B. S. degree in Physics, and M. S. degree in Optical Engineering. The Optics program at RoseHulman was initiated in 1983, and realizing the importance of optical measurement and testing, courses such as Optical instrumentation and testing and fiber optics and application were incorporated. These courses address some aspects of measurement and testing. However, to enrich the Applied Optics curriculum, many new courses have been introduced such as: Applied Optics Projects Lab I, Applied Optics Projects Lab II, Optical Metrology, Semiconductor materials, and Micro-sensors. Further, certificates in semiconductor materials as well as image processing enables the student to expand their background by studying these diverse topics.

Monitoring student learning in a classroom has been the focus of every educational program and historically several methods are used to access the knowledge gained by the students. Consequently educators can use these methods like tests, quizzes, homework, and 
other activities to assign a numerical value to the knowledge gained by the students. This is indeed a task that has gradually evolved in the last several hundred years. In the context of the optical engineering program here at Rose-Hulman Institute of Technology each course relays a level of knowledge gained by the students indicated by the student's grade. These grades could then be used to access the overall learning of the students from his first year to the time of graduation in a given program. This is a cumbersome and rather complicated task that every institution faces. Consequently, a series of concept inventory questions were developed for us to use in assessing the overall learning experience of the students. Rather than test the students in all the optical engineering courses, a smaller set of core courses were chosen to provide a sample that can be used as a good indicator of the overall learning experience of the students in the optical engineering program. In general these concept inventory questions can be used in any optics program.

\section{Concept inventory}

Concept inventory questions as the name suggests test the concepts gained by the students as a consequence of taking a course. Concept inventory questions were first introduced in the Force Concept Inventory pioneered by Hestenes [1]. These questions test the fundamental knowledge of a student in a given subject rather than the ability of the student to memorize an equation or compute a mathematical/numerical result. This is in contrary to the typical questions and problems that are being asked during exams that are usually mathematically regressive. Concept inventory questionnaires have been developed for six optical engineering courses. Students are asked to answer a questionnaire developed at RoseHulman Institute of Technology during the first and last class sessions. The pre-class questionnaire assesses some prior knowledge of the students as well as several key concepts that they will learn in the current course. The post-class questionnaire measures conceptual gains by the students during the class. Concept inventory questions were administered in 200304 for three courses and 2004-05 in all the six courses. The questions are being refined every year to be able to get better data of student learning. The results of the concept inventory have been used by faculty to evaluate their methodology of teaching and the academic departments use it to evaluate the quality of their engineering program. We have also created a dashboard indicator rubric on a yearly basis.

The following core courses have been chosen to administer concept inventory questions and they are: two in the sophomore year (PH 292 Physical Optics and OE 280 Paraxial Optics), two in the junior year (OE 393 Fiber Optics and Applications and OE 450 Laser Systems and Applications) and two in the senior year (OE 495 Optical Metrology and OE 417 Optical 
Engineering Design III). To date, three questionnaires have been completed and two are in process. The results of the completed questionnaires will be discussed in this paper. They are OE 450 (Spring Quarter 2004), OE 495 (Fall Quarter 2004), and PH 292 (Fall Quarter 2004). Examples of questionnaires will be presented as well.

\section{Example of concept inventory test and results}

This is the first intensive optics course students take in the optical engineering program. This course long with OE 280 paraxial optics, and OE 295 optical systems are the foundation courses where students are exposed to a wide range of optical topics. It should be kept in mind that these students have been exposed already to reflection, refraction, lenses, diffraction, and interference in the year long introductory physics courses namely $\mathrm{PH} 111$ physics I, $\mathrm{PH} 112$ physics II, and PH113 physics III. The optics principles are taught to students in the last of physics sequence.

Sample concept inventory questions for PH292 Physical optics are given below. The questions gradually migrate to deeper understanding of optics principles to give a clear picture as to how much a given student has prior knowledge of the subject. This helps the instructor in two ways: i) better understanding of the knowledge base of students in the class and ii) tailor lecture and education to promote learning in weak areas.

\section{Sample Questions:}

Multiple Choice and True/False questions:

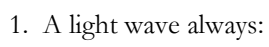

$\begin{array}{lll}\text { (A). has a parallel wavefront } & \text { (B). is an electromagnetic wave } \quad(C) \text {. travels radially away from the source }\end{array}$ $\begin{array}{ll}\text { (D). originates at the point at infinity } & \text { (E). none of the above }\end{array}$

2. When a beam of white light enters a glass triangular prism it:

$\begin{array}{llll}\text { (A). goes straight through the prism(B). is totally reflected at the front surface } & \text { (C). is bent at different angles }\end{array}$ $\begin{array}{llll}\text { based on the wavelength } & \text { (D). is bent at only one angle } & \text { (E). glitters }\end{array}$ 
6. A necessary condition for two waves to interfere is that the waves must:
(A). originate from two different uniform sources
(B). form fringes on a screen
(C). be coherent

(D). be visible (E). all of the above

10. A Mach-Zehnder interferometer can be used to measure:

(A). the deflection of a concrete column

(B). the change in the index of refraction as a function of pressure

(C). the optical quality of a lens

(D). the rotation rate of the interferometer

True/False Questions: Identify the true statements with a $\mathrm{T}$ and the false with an $\mathrm{F}$.

13. The figure below shows diffraction patterns from two different single slits. Slit\#1 is illuminated by light of wavelength $\lambda_{1}$ and Slit\#2 is illuminated by light of wavelength $\lambda_{2}$. The distance between the slit and the viewiffg screen is the same in both cases. Identify which of the following conditions could be true and which are false.
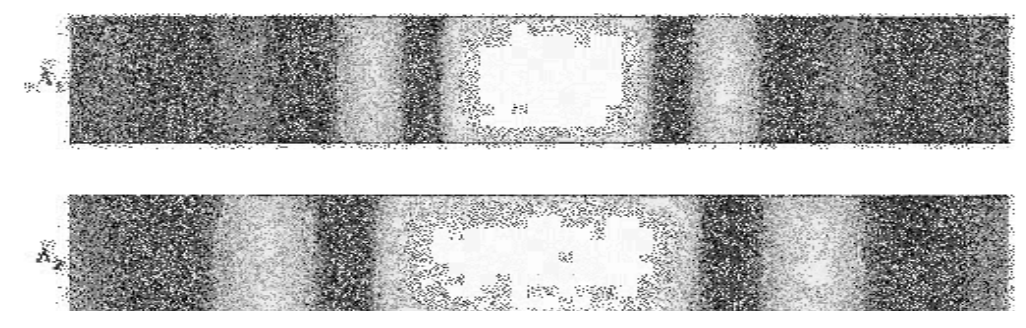

15. When light from a collimated laser is diffracted by a single slit:

(A). the diffraction pattern becomes smaller as the slit width is increased

(B). the diffraction pattern has less contrast if the slit width is increased

(C). the diffraction pattern disappears if you change polarization

(D). the diffraction pattern has uniform intensity

(E). the diffraction pattern has nonuniform intensity

been done in two ways: i) the overall score of each student is compared to pre and post test to identify improvement in learning and ii) individual questions are tallied to see how the overall learning has been in specific areas. The second method provides a detailed picture of student learning. Table 1 shows one such result obtained for PH292 class in fall of 2004-05.

\begin{tabular}{|c|c|c|}
\hline $\begin{array}{c}\text { Score Above } \\
\text { This Percentile }\end{array}$ & $\begin{array}{c}\text { Pre-Class Questionnaire } \\
\text { Number of Students (Total = 28) }\end{array}$ & $\begin{array}{c}\text { Post-Class Questionnaire } \\
\text { Number of Students (Total = 27) }\end{array}$ \\
\hline $90 \%$ & 0 & 6 \\
\hline
\end{tabular}




\begin{tabular}{|c|c|c|}
\hline $80 \%$ & 8 & 14 \\
\hline $70 \%$ & 8 & 4 \\
\hline $60 \%$ & 9 & 3 \\
\hline$<60 \%$ & 2 & 0 \\
\hline
\end{tabular}

\begin{tabular}{|c|c|c|}
\hline & Pre-Class & Post-Class \\
\hline Average & $71.1 \%$ & $83.0 \%$ \\
\hline Standard Deviation & $9.6 \%$ & $10.1 \%$ \\
\hline
\end{tabular}

\begin{tabular}{|l|c|c|}
\hline Dashboard Indicator Rubric & Pre-Class & Post-Class \\
\hline Percentage of Students Scoring $70 \%$ or Above & $57 \%$ & $89 \%$ \\
\hline
\end{tabular}

Table 1: Shows the results of the concept inventory test results for PH292 Physical Optics (Fall 2004-05)

The pre and post class averages indicate that there is definite increase in the student understanding of the concepts being taught in the class. Less that half the class scored below $70 \%$ in the pre-test and more than $85 \%$ of the class score above $75 \%$ in the post test. Tables 3 and table 4 show the pre and post test scores for a junior and senior level class.

\begin{tabular}{|c|c|c|}
\hline $\begin{array}{c}\text { Score Above } \\
\text { This Percentile }\end{array}$ & $\begin{array}{c}\text { Pre-Class Questionnaire } \\
\text { Number of Students (Total = 15) }\end{array}$ & $\begin{array}{c}\text { Post-Class Questionnaire } \\
\text { Number of Students (Total = 14) }\end{array}$ \\
\hline $90 \%$ & 0 & 0 \\
\hline $80 \%$ & 0 & 2 \\
\hline $70 \%$ & 0 & 0 \\
\hline $60 \%$ & 1 & 7 \\
\hline$<60 \%$ & 14 & 7 \\
\hline
\end{tabular}

\begin{tabular}{|c|c|c|}
\hline & Pre-Class & Post-Class \\
\hline Average & $37.6 \%$ & $57 \%$ \\
\hline Standard Deviation & $16.4 \%$ & $15.3 \%$ \\
\hline
\end{tabular}




\begin{tabular}{|l|c|c|}
\hline Dashboard Indicator Rubric & Pre-Class & Post-Class \\
\hline Percentage of Students Scoring $70 \%$ or Above & $0 \%$ & $14.3 \%$ \\
\hline
\end{tabular}

Table 2: Shows the results of the concept inventory test results for OE 450 Laser Systems (Fall 2004-05)

\begin{tabular}{|c|c|c|}
\hline $\begin{array}{l}\text { Score Above } \\
\text { This Percentile }\end{array}$ & $\begin{array}{l}\text { Pre-Class Questionnaire } \\
\text { Number of Students (Total = 8) }\end{array}$ & $\begin{array}{l}\text { Post-Class Questionnaire } \\
\text { Number of Students (Total = 7) }\end{array}$ \\
\hline $90 \%$ & 0 & 0 \\
\hline $80 \%$ & 0 & 2 \\
\hline $70 \%$ & 1 & 3 \\
\hline $60 \%$ & 0 & 2 \\
\hline$<60 \%$ & 7 & 0 \\
\hline
\end{tabular}

\begin{tabular}{|c|c|c|}
\hline & Pre-Class & Post-Class \\
\hline Average & $40.6 \%$ & $60.7 \%$ \\
\hline Standard Deviation & $18 \%$ & $10.4 \%$ \\
\hline
\end{tabular}

\begin{tabular}{|l|c|c|}
\hline Dashboard Indicator Rubric & Pre-Class & Post-Class \\
\hline Percentage of Students Scoring $70 \%$ or Above & $12.5 \%$ & $28.5 \%$ \\
\hline
\end{tabular}

Table 3: Shows the results of the concept inventory test results for OE 495 Optical Metrology

(Fall 2004-05)

\section{Conclusions}

Data presented for all the three courses from the sophomore to the senior year show improvement in students being able to clearly understand concepts in several areas of optics. Of all these courses $\mathrm{PH} 292$ results shown in table 1 has a result that is of value to an educator. This could have been due to the fact that the students had some prior knowledge from their freshmen class as well as the teaching ability of the instructor. Further, questions in the upper level classes such as OE450 and OE495 could have been not fairly distributed and are more specific in terms of subject content. However, we are in the process of further refining the questions to broadly represent the various subject materials of the students.

\section{Acknowledgments}

The Authors thank several of the faculty members in the department who have helped in developing and administering concept inventory test in their respective classes.

\section{References}

1. Hestenes, D., Wells, M. and Swackhamer, G., "Force Concept Inventory," The Physics Teacher 30, 141 (1992). 